\title{
Exploration of CIS middle school class moral education pattern based on the perspective of youth development planning.
}

\author{
He Yan ${ }^{1, a, *}$ \\ ${ }^{1}$ Longsai senior middle school, Ningbo, China \\ awkw1995@163.com, \\ * He Yan
}

Keywords: The Plan of Youth development, Middle school, Moral education, CIS.

\begin{abstract}
This paper based on Medium and long term plan of youth development (2016-2025 years), aiming at the new requirements and measures of young people's ideological and education , probes into a new method of moral education in middle schools. We Start from the class work, drawing on the experience of the CIS theory and the idea of Borad-Baseded Education. The result shows that "Visual recognition, Common behavior, Shared environment" enhance the sense of belonging within the class as a significant role .
\end{abstract}

\section{青年发展规划视域下探索中学CIS班级德育模式 \\ 一以 “博雅立行” 特色教育为例 \\ 何燕 $1, a,{ }^{*}$ \\ 1浙江省宁波市龙赛中学, 宁波, 中国 \\ awkw1995@163.com \\ *何燕}

关键词：青年发展规划, 中学, 班级德育, CIS

中文摘要. 本文结合《中长期青年发展规划（2016-2025年）》的出台背景, 针对其中关于青 年思想道德、青年教育的新要求新措施, 探讨中学德育的新方法。从微观班级德育工作切入, 引入CIS理论与博雅教育的理念, 围绕龙赛中学特色教育的案例, 发现“视觉识别、行为同向、 环境共建”的建设方法对于加强青年获得感，增强班级内部的归属感有显著的作用。

1. 引言

2017年上半年国家《中长期青年发展规划（2016-2025年）》正式发布。规划指出要加强 青年理想信念教育, 分类开展青年思想教育和引导工作。将增强学生社会责任感、法治意识、 创新精神、实践能力作为重点任务贯彻到学校教育全过程。这也对当前中学德育工作提出了 迭代革新的时代要求。为此, 浙江省特色示范中学龙赛中学借鉴欧美Borad-Baseded Education 教育思维, 融合传统文化中的博雅思想, 引入CIS理论即现代企业经营战略系统的思路, 从精 神文化、行为文化、环境文化三方面入手，努力革新。其创新手段及实践经验对于同类普通 高中的德育工作具有较大的借鉴意义。 


\section{CIS德育理论的应用背景}

CIS理论即corporate identity system, 最初产生于企业管理领域。主张把团体形象作为一个整 体进行建设和发展, 注重理念识别 (mind identity) 、行为识别 (behavior identity) 、视觉识 别 (visual identity) 三部分 ${ }^{11]}$ 。CIS理论的早期实践可以追溯到1914年德国的AEG电器公司。 AEG在其系列电器产品上, 首次采用商标, 打造集体文化, 为现代企业 (团体) 统一感知形 象首开先河。在中学德育工作中, 同样可以按照CIS理论的指导思路, 构建具有一定影响力和 号召力的班级集体。对内发展学生, 对外辐射全校, 形成德育的泛化感染力。

\section{1 惯性思维下中学班级德育存在的负面趋向}

随着基础教育改革的进一步推广，德育工作在中学整体层面的推进力度大大加强。但就 微观层面而言, 尤其是在以班级为主体的德育体系构建中, 依旧存在着传统上“以班主任为中 心”的特征。一方面是因为在中学阶段缺乏切实可用的方法论, 另一方面与一直被媒体脈病的 “班主任生态”也有关。班主任渐渐成为学校职能部门的行令执行者, 而德育工作者的角色被 繁重的事务性工作所弱化了。加之, 中学班级德育存在一股影响力较大的惯性思维, 即德育 的根本目的是为了服务于学习, 它是保障考试成绩的一大抓手。这也造成了以下的几大负面 趋向:

\subsection{1“控制主义”倾向}

根据社会学的观点, 控制是社会组织体系运用社会规范和与之相应的手段和方式, 对各 类社会关系进行的调节, 对社会成员的社会行为和价值观念进行的指导和约束。[2]但在班级 德育的现实工作中，“控制”常常会因为忽视了班级的特殊性，而走向极端。把学生往“死”里 管，管“死”了，压缩了他们最后的一点自主发展空间。控制主义的表现包括在班级建设中最 关心的是班级中的纪律、操行、量化评分等学生的外部表现。通过封闭的绝对控制, 监管学 生的一举一动, 达到学生的整齐划一。经在浙江省 $\mathrm{N}$ 市 Z 区 3 所高级中学的实地调查发现, 43 个班级中有超过 37 个班级采用了评分方式来监督学生的“品行”, 有约 $76 \%$ 的班级将日常 的品德分纳入了期末 (年度末) 学生三好学生等个人表彰的评比活动。不可否认这些措施对 于增强德育的实效性有客观帮助, 但匿名调查显示, 各个班级中德育评分细则的平均满意度 仅为 $18.3 \%$ 。

\subsection{2“管理主义”倾向}

不少中学德育工作者在潜意识中是将“管理主义”作为指导原则的。即认为加强对学生的 管理与控制是解决各种教育问题的基本途径和主要手段。很少顾及学生自身的实际需要。尤 其在班级德育层面, 习惯将学校的整体部署“灌输式”地一股脑应用在班级里。这样的操作忽 视甚至无视了受教育者的主观能动性, 追求的不是使受教育者因为受到教育而积极自觉地去 理解、选择、追求道德规范, 而是表面上的顺从, 实质是消极地接受和被动地服从。例如, 五点起床跑操、上则所不许结伴等规定, 实际上极易引发师生之间、生生之间的对立情绪, 而管理者在出现问题时往往会据此再一次加强对学生的管理, 如此反复, 产生恶性循环。在 表面上看也能保证班级教育活动的平稳有序开展, 但实际上留下了许多隐藏在背后的教育学 视角下的弊端。严格意义上说，这种德育的惯性思维是存在反教育性倾向的。

2.1.3“工具理性主义”倾向

在素质教育、新德育等理念的推进下, 我们不可忽视工具理性主义倾向, 即重视对效率 的追求。目前在班级德育过程中, 为了确保管理教育的长效性, 不少学校及老师开始将班级 制度的建立放在首要位置。其实, 制度化班级管理隐藏着“目的一工具”的思维逻辑。如果 制度缺乏论证、科学性、执行者过于急功近利, 很容易激发工具理性主义的思想: 只要能够 简便有效地达到相应的目的就好, 不论手段是什么。它关注的是直接目的的达成, 而不考虑 其合理性。“教育者往往以控制和要求代替理解和沟通, 考虑的不是个体的需要, 而是制度的 不容侵犯”[3]。它损害了学生的主体性, 忽视了学生能力的培养。 


\section{2 青年发展规划与班级德育革新的耦合性}

《中长期青年发展规划》（下文简称为《规划》）的出台对青年思想道德、青年教育提出 了系统科学的规划和要求, 同时也为纠正中学班级德育工作上述的不良倾向, 制造了良好的 契机。从耦合的角度看, 两个 (或两个以上) 系统或运动形式通过各种相互作用会发生彼此 影响的现象。而青年发展规划对于中学班级德育革新的主要影响可概括为以下三个方面。

2.2.1 把握学校青年多元化、个性化的发展需求

《规划》指出学校教育的落脚点是要教会青年学生生存生活的技巧, 做人做事的方法, 指 引他们了解社会, 适应社会。[4]着重提到了在全社会推动形成“鼓励青年多样化参与、支持青 年个性发展、宽容青年失误”的氛围。为此, 班级德育在革新过程中应当把握青年学生多元化、 个性化的发展需求。在落实系统的课程教育的基础上, 鼓励引导“扬长教育”, 发掘学生的个 性特长。在班级中通过开展小规模的“对话人生”、“今日小擂主”等活动, 让学生在班级内获 得更多的存在感和出镜率。这里的“长处”不仅仅是音体美方面的艺术性特长, 还包括日常生 活中的小技巧、人际交往中的小本领, 例如缝纽扣, 礼貌地问好等。以班级为主体的班级德 育可以弥补以往学校层面进行的艺术比赛、体育竞赛, 让更多默默无闻的孩子重拾自信, 展 示个性。

2.2.2 抓住虚拟网络活跃性、创造性的交互特征

如今教育信息化工作不断推进, 新技术、新载体、新理念正在持续地影响教育改革。尤 其是面对越来越多的青年学生受到移动互联网影响这一社会现实, 利用新媒体扩大育人实效 对中学德育而言已迫在眉睫。据腾讯浏览指数平台数据显示, 热门游戏《王者荣耀》近 2 亿 用户中，18 岁至 23 岁的用户占比 $37.38 \% ， 13$ 岁至 17 岁的用户也超过了 $18 \%$ 。可见青年学 生对网络游戏的沉迷程度。在《规划》中, 也提到了教育者要注重运用网络新媒体扩大宣传 教育覆盖面。教师要引导青年正确认识网络空间与现实社会的关系, 多到社会实践中长见识、 练本领。因此, 在班级德育工作中如何利用新媒体技术和互联网思维, 抓住青年学生热衷于 虚拟网络互动、习惯于在虚拟空间内进行社交等特点, 从而发挥自己引路人的作用是一个重 要的议题。

\subsection{3.注重素质教育全面观、整体观的改革趋势}

《规划》在《指导思想》中强调要促进青年全面发展, 引导青年树立共产主义远大理想 和中国特色社会主义共同理想, 坚定中国特色社会主义道路自信、理论自信、制度自信、文 化自信, 自觉团结凝聚在党的周围。在《根本遵循》中提到, 要让青年有更多获得感, 促进 青年在投身实现中华民族伟大复兴中国梦的实践中放飞青春梦想、实现全面发展。而高中阶 段 (15 周岁-19 周岁) 是青年价值观、世界观养成的重要阶段, 也是目前素质教育改革推进 的关键一环。所以班级德育工作应当借助《规划》出台、推进、落实的这一契机, 坚持全面 观、整体观的改革趋势, 促进青少年全面发展。而 CIS 德育理论适用范围广, 关注个性化的 同时还能突出集体 (群体) 的优势特征, 可以有效地抓住上述耦合点, 从而解决当前出现的 不良倾向。

\section{CIS 德育理论的实施原理}

将 CIS 理论引入中学德育, 所产生的德育理论与其原生状态时已经发生了较大变化。CIS 德育主要由三部分构成: 视觉识别、行为同向、环境共建。[5]这三个层面存在着依次递进的 关系, 遵循思想政治教育的认同理论。在具体应用时需要本着先建立共识, 后开展同行, 再 凝聚共同力的思路。它的核心思想是帮助每一个青年学生建立归属心, 增加他们在学校班级 内部的个体获得感。

\section{1 以识别促认同}

从思想政治教育认同理论的内涵来看, 认同是社会大众基于内心自愿的基础上对教育活 
动及其运作持有同向性的情感、态度并采取相应广泛支持行为的活动过程。[6]就中学德育活 动而言, 学生的认同感其实直接关系到德育工作的实效性。而提高认同感的第一步就是运用 CIS 理论中的视觉识别手段。高中学生正处于青春期, 对于事物的认识过程中感性成分较重。 而视觉识别可以有效地吸引他们的注意力。例如, 共同设计班级的班旗、标识 LOGO, 对班 级教室内外部进行创意布置及增添校饰品等都是加强他们视觉识别的重要手段。在视觉识别 之后, 教育对象会逐渐对班集体建立情感共识。在情绪、情感、心境上对班级管理表现出来 的肯定或否定、满意或拒斥、热爱或憎恨、赞赏或厌 恶的心理倾向。

\section{2 以认同培行为}

德育活动是否被认同，不仅要看学生在思想观念形态即认知层面、情感层面是否认同思 想政治教育, 还要看他们的言行是否遵循德育工作所指示的方向及具体要求, 着重关注价值 层面和行为层面。CIS 德育理论的第二部分是行为同向, “同向”即共同的目标或方向。要求 教育对象在取得对班集体 (团体) 的视觉识别后, 从价值取向和行为表现两方面进行再认同。 然后, 由班主任组织开展具有同向意义, 学生们喜闻乐见或能够理性理解的共同性行为。比 如在晨读时融入 “经典诵读”的内容, 在晚自习前加入“吾日三省吾身”的环节等, 需要在学生 认同其价值的基础上开展, 从而确保活动的实效性。行为的同向是价值、情感、抽象理念等 认同的基础和必要保证。在中学德育活动中, 如果离开相应的行为, 那么其他环节的识别与 认同也就失去了坚实的着力点, 对教育主体和思想政治教育系统不具有任何实质性的作用意 义。

\section{3 以行为育环境}

CIS 的第三步在于环境共建。中学班级德育是一个多维主体的结构。班主任、任课老师、校 方德育工作者、精英学生与普通学生, 彼此是在一个有限的物理空间和无限的心理空间内完 成交集的。在过去的实践中, 我们所注重搭建或改良的环境大多为教室内的物理环境, 极少 涉及学生的心理环境, 更是很少干预班级内隐形的但确实存在的学生层级。而 CIS 从识别、 认同、同行的角度出发, 可以说为这方面的构设提供了一个良性的干预契机。不过, 若采用 过去单纯进行班级文化建设或励志教育的方法, 很可能会导致青春期学生存在一个逆反心理。 而 CIS 循序渐进的思维可以让教育者应抓住机会, 甚至尝试跨部门联动, 利用新媒体技术等, 很好地利用班级内不同价值观、不同学生个体、不同行为在交流碰撞中所产生的张力、冲突 和一致性, 大大改善现有的班级德育环境。
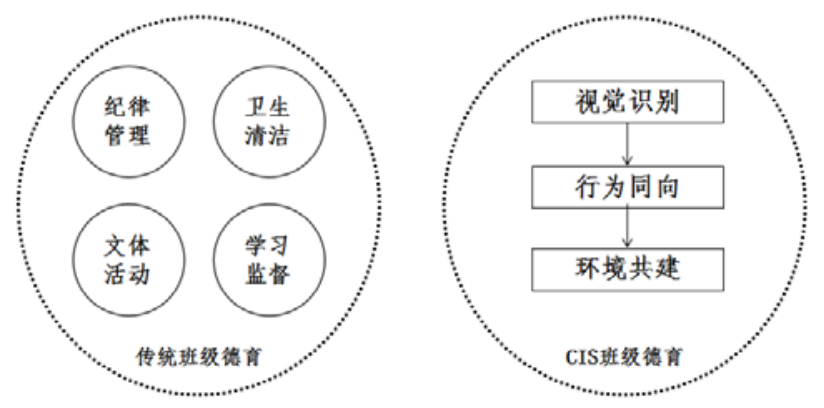

图 1 为传统班级德育同 CIS 的思路比较

\section{CIS 德育理论在中学班级的应用实践——以博雅立行特色教育为例}

基于以上背景及理论要点, 浙江省龙赛中学作为一所特色示范性学校在借鉴 CIS 德育理 论的基础上积极开展实践活动。作为一所高级中学, 龙赛中学在区内属第二批次招生, 在生 源上无法与同区的镇海中学 (浙江省排名第一) 相比。为此学校从学生“失意者”、“落榜者” 的心态出发, 结合《中长期青年规划》, 在原有的励志教育的基础上, 首先在高一年级 $\mathrm{W}$ 班 试行“博雅立行”特色教育。即引导学生内外兼修、学以致用、勇于实践、雅正于行, 注重实 
践和博通。具体应用措施如下:

\section{1“博雅立行”特色教育中 CIS 德育理论的实施策略}

\subsection{1 理念层: 融入博雅教育思想, 知行合一}

考虑到自身实际情况，高一 $\mathrm{W}$ 班在贯彻“视觉识别、行为同向、环境共建”三步骤的基础 上, 增加了“凝聚共识”的一环。由班主任牵头开展了理论学习的相关工作。首先确立教师们 的核心育人观, 以文字的形式明确班主任的带班理念, 并依照自身的带班理念对班级的管理 目标、美好愿景进行合理的规划。可引导出系列目标, 从大到小, 层层落实, 并与其他任课 老师进行沟通, 以实现协同的效果。在高一 $\mathrm{W}$ 班, 就将带班理念归纳为“雅量高致, 腹有诗 书; 增进学业, 修养人格”, 并据此制出《日省录》配合目标的实施。

从概念上来看，博雅立行特色教育中所提倡的“博雅”并非希腊的古典博雅教育，而更偏 向于现代西方的博雅“博通”教育。[7]鼓励学生广泛地涉猎知识, 同时需要教师改进教育理念, 包容学生多样化的兴趣特长，例如“纸飞机”、“五子棋”、“拆东西”等等。在传统观念中，被 视作雕虫小技甚至是玩物丧志代名词的那些爱好应该在博雅教育的体系中获得教师的认可。 秉持“激发学生创造力, 保护学生想象力”的思想, 班主任努力做好引路人的角色。在高一 $\mathrm{W}$ 班, 班主任就将中国 (宁波) 纸飞机大赛、 $\mathrm{OM}$ 头脑奥林匹克等赛事及专业竞技类的活动介 绍给学生们, 引导他们的兴趣爱好获得良性发展。目前班级内已有超过 90\%的同学加入了校 内的各类社团。

4.1 .2 视觉层: 强化班级精神建设, 以文化人

在视觉识别层面, 高一 $\mathrm{W}$ 班从设计班级 LOGO、班旗、班训入手。在这个过程中, 班主 任主要起引导作用, 由学生作为创意和集成的主力军。与通常的学生主导型设计不同, 在具 体操作中，高一 $\mathrm{W}$ 班采用了“团体诘问”的方式。由学生自主提出多个选题或方案，进行“无 领导小组讨论”, 再由集体讨论决定。教师着重参与班训内容和班旗寓意、LOGO 设计理念这 部分内容。通过这种方式激发学生的全面参与, 让班主任核心育人观深入思想建设的细节, 不断内化为学生的实际行动。这样无论学生有无创意思想、美术功底, 都可参与到班级核心 视觉产品的讨论中, 易激发主人翁精神。

4.1.3 行为层: 形成内在行为文化, 自主约束

“行为建设”是高一 $\mathrm{W}$ 班开展实践过程中遇到困难最多的一个环节。根据入学时的数据统 计 $\mathrm{W}$ 班有超过 55\%的学生来自于外地, 有 $6 \%$ 左右的孩子属于无学籍借读。彼此之间的风俗 差异和生活习惯存在较大差异。如何找准群体内的共通行成了摆在班主任面前的一个难题。

考虑到学生群体中有超过 25\%的同学在心理普测中存在阳性症状，其中“强迫症状”、“偏 执”、“敌对”的因子得分最高, 最高超过 4.17。结合家访活动发现其主要原因在于原生家庭的 内部关系。因此, $\mathrm{W}$ 班决定以家庭作为同向活动的突破口。举办了感恩家书家信的征集活动, 邀请家长与孩子分别书写给对方的家信。对于部分由于文化水平较低无法独立完成撰写活动 的家长, 在班主任的组织下开展了“有声家书”, 通过录音的方式作为补充。活动含评选、部 分章句展览、共同践行等环节, 持续一个多月, 获得了较好的反响。此后, W 班开始将同向 活动由家庭感恩这一主题转向班内。围绕礼仪、高效学习、国学知识等内容开展同向活动。 在这样的同向活动中逐渐在班级内部分化出了不同角色，例如组织者、后勤保障员等。并由 此完成了入学后的第二次班委选举，具有凝聚力的班集体正式形成。

4.1.4 环境层：构筑良性品德生态，环境育人

为了确保 CIS 德育理论获得持久的效果。W 班积极构筑班内的品德生态。在物理环境方面, 主打“自然教室”、“文明书桌”两个办法。一方面融入自然教育的核心理念, 在班级里设置了 绿植角。虽然班级绿化无论是种类还是面积都难以同外界相比，但定期开展的“花语接龙”活 动、“青春诗歌”创意比赛可以很好地培养教室内的生态氛围; 另一方面则是通过统一购置“书 袋”的方法, 解放学生“课桌”, 保持教室内的整洁卫生。

在虚拟环境方面, 利用微信公众号, 开设“过招青春期”、“社会情感学习”等栏目。把以往学 
校教育类公众号常推的心灵鸡汤类、学习技巧类、成功案例类的内容置换成了由班级学生或 家长主动创作的日记、好文分享、百科知识普及等。以往新闻热点、社会奇闻等被视作容易 干扰学生学习的内容全部纳入 $\mathrm{W}$ 班的分享体系中。这样既保证内容贴近生活, 又贴近内心。 通过教师的合理操作和内容设计可以有效地避免负面影响, 从而遵循博雅教育中广博的理念。

\section{2 实施策略中的应用要点}

\section{2 .1 创新组织范式，打造“多中心同心圆”}

CIS 德育理论的应用中要注意班级内部角色的转化。过去常规的班级活动中, 班主任是 主导地位, 而学生更多时候扮演的是服从者的角色; 近期在教育改革如火如茶的背景下中, 大多数学校开始尝试以学生为主体。这一思想固然没错, 但在一线操作时会发现, 在赋予学 生主动性, 强调学生起主导作用的过程中, 真正起作用的往往只是班级内的尖子生, 对占据 班级人数 $80 \%$ 的普通学生没有太多的影响。CIS 德育体系的一个基点就是要帮助绝大多数的 个体建立归属心, 增加他们在学校班级内部的获得感。因此上述的两种组织范式均不能在 CIS 理论的实施过程中照搬照用。

在 CIS 中学班级德育的模式中, 班主任与学生、学生与学生之间不能是单向联系与被联 系的关系, 管理与被管理的关系。彼此之间的互动反馈、双向交流显得更加重要。考虑到一 线工作极有可能出现各种突发情况, 班主任在该模式中依旧要处于“把握方向盘”的地位, 起 主导作用。学生同样可以是一个节点, 成为一个动态具有流动性的活动中心。简单而言, 青 年学生的活动中心地位是根据实际情况的不同而不断更迭变化的。例如在文体活动中, 拔尖 的会是有文艺特长的同学, 而在野营春游时, 拥有生活技能多的同学就自然成了彼时的中心。 而学校的博雅教育, 可以为实现这种范式提供了较好的机会和条件。

4.2.2 利用社交网络, 实现“家校”共育

CIS 德育理论虽然应用的载体是班级, 但不可忽视原生家庭的影响。随着异地高考、异地上 学门槛降低, 教育人口流动也越来越频繁。这也意味着班主任需要尽力弥合不同文化背景、 家庭背景、生活经历的学生们之间存在的个性或共性的差异。而在这一过程中, 家庭教育扮 演着不可或缺的角色。因此班主任应顺应信息化的潮流, 利用微信群、QQ 群或开设微信公 众号等方法构建家校联动的平台。充分发挥家庭教育在班级德育外围的铺垫作用。这是 CIS 德育理论“共建环境”的重要保障。从 $\mathrm{W}$ 班的实践情况来看, 班主任与家长群体的点对面的沟 通保持在一天 2 次至 3 次为宜, 包括学生成绩、课堂表现、饮食住宿情况、兴趣爱好选修课 等多方面的信息。但是要注意联系次数过多则会增加家庭教育的负担, 过少则会影响班级德 育实效性的发挥。

4.2.3 力推个性化策略, 避免“班人”同化

在 CIS 的识别过程中, 实践者会不自觉地注重个体对集体的归属感。无论是视觉识别, 还是行为同向均包含了要求对集体性的强调。但这并不意味着可以忽视个体的个性化培养。 为了避免在“班级人格化”，打造班级特色中损害青年学生个体发展的空间, 班主任需要因材 因时制定个性化的培养策略。即使做不到对每一个学生都量身定做“培养方案”，也可以借鉴 龙赛中学 $\mathrm{W}$ 班的方法: 利用计算机 SQL 数据库等软件, 对学生进行点对点的跟进, 及时了 解其动态。另一方面每隔一个月, 与学校后勤部门对接掌握其在校园内消费、借阅等情况, 在硬件设施还不够完善的现状下尽可能地运用大数据的理念, 全方面地了解学生, 做到有针 对性。避免出现班人合一的“倒退”现象。

\section{5. 中学 CIS 班级德育模式的概述及推广意义}

中学 CIS 班级德育模式：是以信息化的教育技术为支持，以实体活动介入为路径，以班 主任 (指引者) 与青年学生 (对象) 之间的联动为纽带, 利用现有的教学资源、班级德育环 境、新媒体平台, 开展“视觉识别、行为同向、环境共建” 的重要载体; 其核心功能是融合博 
雅教育理念, 分享知识信息、完成精准育人、实现青年全面发展。针对当前班级德育工作脱 离青年学生这一现实问题, 进行多视角联系, 最终建构一个纵横协同、高效运行的班级德育 系统。

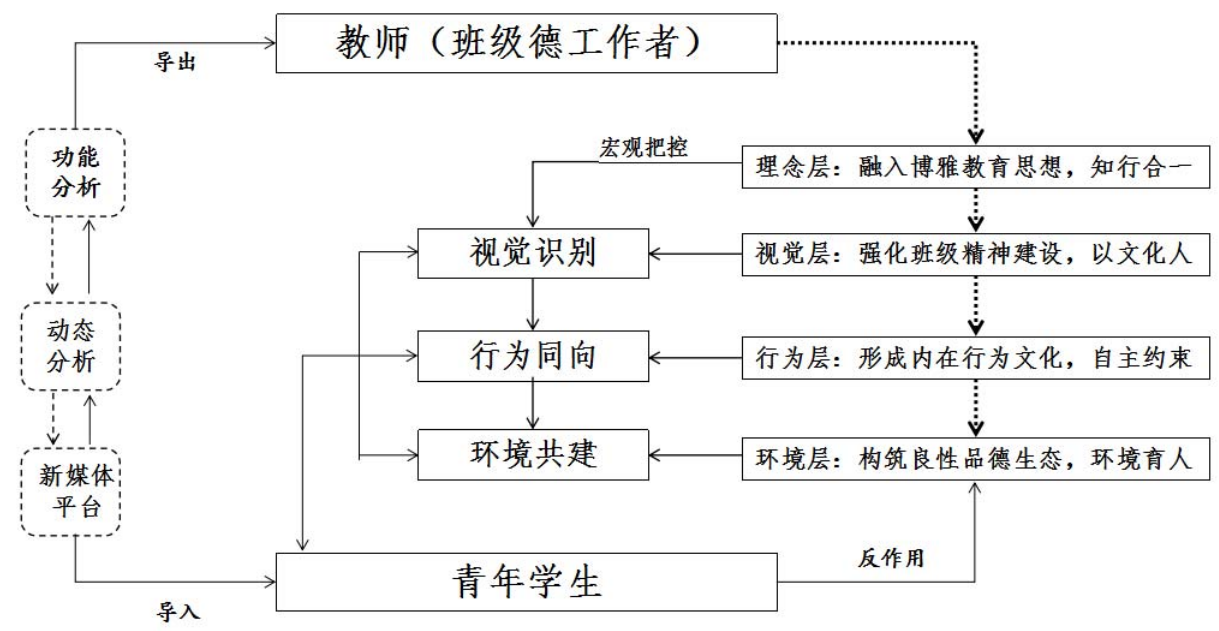

图 2 为 $\mathrm{CIS}$ 班级德育模式的简图

此模式的出发点在于协同互利, 重点关注青年学生在中学阶段的获得感和归属感, 从学 校生活中逃脱不掉的话题“班级”作为微观载体，着眼于青年成长，利于探索中学班级德育的 新方式。事实上, 中学 CIS 班级德育模式并不是对中学德育工作提出颠覆式的构想, 它更多 是针对《中长期青年发展规划》在中学层面具体推进过程的一种建议。希望通过一种育人模 式上的创新对中学的青年培养工作进行资源整合、流程再造、提高教育的质量和实效。

\section{References}

[1] Ye Changjuan, Enterprise Culture Based On CIS Theory, Chinese and Foreign Entrepreneurs,vol.19, pp.186, 2015.

[2] Yang Rui, Status, Problems And Countermeasures Of High School Class Management, Master's Thesis Of Central China Normal University, 2013.

[3] He Juling, Research Paradigm Of Education Teachers, Master's Thesis Of Shaanxi Normal University, 2008.

[4] Tan Yi, the policy of "Chinese Medium and long term plan of youth development (2016-2025 years) ", China Youth Study, vol.9, pp.12-18, 2017.

[5] Song Jie, The Application Of CIS In The Ideological And Political Education, Technology And Development Of Enterprise, vol.2, pp.97-99, 2010.

[6] Wei Yongjun, The Identity of Ideological And Political Education Research. Master's Thesis Of Hohai University, 2007.

[7] Chen Jianhua, Study On The Western Liberal Education Tradition And Its Evolution. Social Sciences In Nanjing ,vol.8, pp.124-130, 2016. 